\title{
Development of an Educational Software as Support for Learning English and Mayan Languages through the use of the Kinect Sensor
}

\author{
Lizzie E. Narváez Díaz ${ }^{1}$, Diana B. Colli Pool ${ }^{2}$, Manuel J. Escalante Torres ${ }^{3}$, Victor M. Chi Pech', \\ Michel García García ${ }^{5}$
}

Faculty of Mathematics, Autonomous University of Yucatán, Mérida, Yucatán, México ${ }^{1-5}$

\begin{abstract}
In the educational environment, the student and the teacher have a very important role in the teaching-learning process for the development of their skills, leading to the development of significant approaches that involve new forms of learning allowing a playful interaction with students, where they learn about new technologies. The aim of this paper is to show a basic tool as a teaching-learning strategy that will allow students to interact with the computer and Kinect, allowing the development of skills and gaining knowledge of English and Mayan language. The interface presented to the student is friendly and intuitive, so the student can learn and have fun at the same time. It's intended that this software improve the teaching-learning strategies and teachers can implement it in the classroom.
\end{abstract}

Keywords: ICT, Educational software, learning, teaching, Scratch and Kinect.

\section{INTRODUCTION}

Currently the use of technology is expanding on a large scale and this is included in most of our daily activities changing the traditional way of performing them, for example, incorporating more efficient working strategies to improve the quality of life of people. In this sense it is held that technological advances are highly related to all areas of knowledge and therefore, of society; being the computer one of the main tools employed to allow the communication and management of information through different software.

Some schools promote interactive teaching, with the clear intention that this will lead to improvements in student learning. Technical and pedagogical interactivity points to a path towards a greater focus on learning objectives during classroom activities, in order to enable students to be more autonomous in exploiting the possibilities of Information and Communication Technologies (ICT) [1].

Educational software (ED) is defined generically, as applications or computer programs that facilitate the teachinglearning process. Some authors conceptualize it as any computational program whose structural and functional characteristics support the process of teaching, learning and managing, or that which is intended for teaching and selflearning, and which also allows the development of certain cognitive skills [2-3].

Some previous works that impact the developed work are:

In [4], an educational software for teaching and learning mathematics is proposed as a solution to improve knowledge of the same through the use of information and communication technologies. The software, which contained a pedagogical component and a technological one, was of great help in the acquisition of mathematical knowledge in an educational institution in the municipality of San Agustín in Colombia, since it had a great impact on the teaching of mathematics. That work relates to the present because students had a tool that accompanied them in their learning process.

The work "Educational Software: Methodology of Development and Incorporation into Learning Environments" [5], presented in a symposium of development and new technologies, describes a process carried out in the generation and development of Educational Software ideas, which support the development of cultural values within the school learning environment proposed by the Connections Project. It presents a methodology and its implications at the level of procedures and techniques that are reversed in two practical cases: "Magic Country" and "Museum Tour". As an important point, this work developed an interdisciplinary methodology that allows the creation of a framework in which each process of creation and development of educational software is enriched, and the proper use of the information and communication technologies.

In [6] it is described the development of a project called: "Educational Software for the Good Use of ICT", which focuses on the creation of special software for elementary school children, through which they learn using interactive tools, and which teaches them to use ICT responsibly.

It should be mentioned that, the learning supported by this type of teaching resources, definitely has a positive impact on the way children capture the contents, in the willingness they show to deepen the topics and enrich their knowledge by researching in other sources of information, activating both their curiosity and imagination. In conclusion, it was obtained that the use of new technologies represents an important resource, almost essential for teaching, as they provide facilities 


\section{International Advanced Research Journal in Science, Engineering and Technology}

Vol. 6, Issue 11, November 2019

for more practical and effective learning. The software for the good use of ICT was designed so that primary school children understand the importance of taking advantage of the internet, and all other technologies (mobile phone, smartphone, electronic tablet) in a responsible way, so as not to fall into situations that could harm them. [7]

In [8], a technology platform for interactive learning of the Mayan architecture is presented, the development of this platform makes use of a Kinect device. In this work the integration of two modules was carried out, the first of them obtains and analyzes the movements of the users and converts them into commands. The second one displays the menus and the contents of each section according to the gestures made by the user. This development allows to interact with multimedia and 3D content in order to learn in a different way topics related to the Mayan architecture. Several Kinect interaction frameworks were evaluated, and it was found that the FUBI framework allows to easily use different gestures, and a combination of them, to interact with any application through the Kinect SDK.

When evaluating the user experience after interacting with the platform of the previous work [8], it was verified that by allowing to interact with 3D models, people can be encouraged to learn more about a particular topic. This previous work impacts in two important aspects of the approach presented in the current work: the Mayan culture and the use of Kinect. The software proposed in this article is an educational software in which the student will be able to interact with the computer and Kinect, means with which he will develop skills and gain knowledge of the English and Mayan languages. The interface presented to the student is friendly and intuitive so that the student can learn and at the same time have fun. It is intended that this software improves the learning strategies that teachers can implement in the teaching-learning process in the classroom as a basic methodology to enrich the development of the country. The main screen of the developed software is presented in Figure 1.

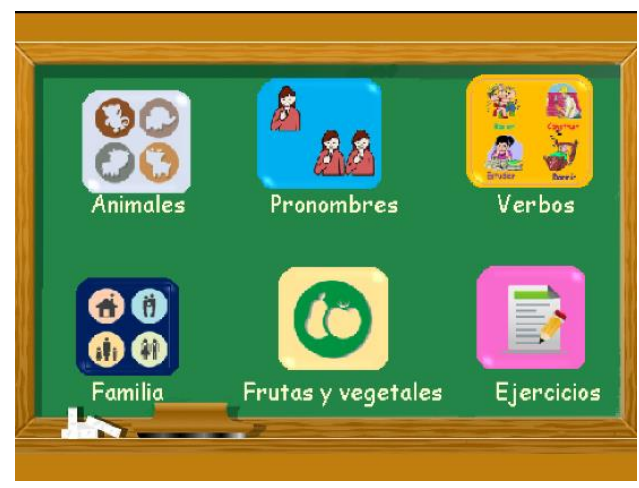

Fig. 1 Main screen of the proposed software

\section{Mayan culture and technology}

The study of mayan culture is of vital importance and is seen in our environment as a practical consequence of the development of its knowledge. Mayan science and technology have been closely related to the development of knowledge and instrument creation for many years by our ancestors.

The Mayan culture were in constant search for truth and collective well-being, based on balancing the relationships between people and mother nature, so the development of Mayan science and technology is a necessary condition for achieving the social, integral and sustainable development of the Mayan people. At present, society has had a great positive impact on education due to the influence that Mayan thought has had.

As the social context and our time is different, new science and technology seeks to promote education in science and technology at all educational levels by developing new projects starting from our present and taking into account the knowledge of the culture that contribute to the proposed purpose and thus disseminate the scopes of science and technology so that it can bear fruits, not only in the Mayan culture but in other contexts where it were applicable. [9]

It is important to value the knowledge and elements of one's own culture, providing and developing knowledge to contribute to various technological advances and to rescue our culture. Therefore, the software presented in this paper is an option in the educational field since it takes into account the Mayan culture which is of paramount importance in the context of application and promotes the identity and heritage of the community.

\section{MethodS AND MATERIALS}

The main objective of this work is the development of an educational software which can serve as support for learning English and Mayan languages through the use of Kinect.

Once the development is complete, the educational software could be used as a technological tool in the classroom as a learning strategy. In particular, it would be very useful in schools located in Mayan-speaking communities, where it is difficult for the secondary and high school student to learn another language, which in this case is English.

In order to achieve the proposed objectives, the following methodology is proposed: 


\section{International Advanced Research Journal in Science, Engineering and Technology}

Vol. 6, Issue 11, November 2019

\section{A. Bibliography review}

The revised literature for the project development was obtained from the consultation of electronic books and reliable internet pages, both on ICT and on technological tools.

\section{B. Tools}

When carrying out the planning of this project, the choice of the tools to be used was made, which are:

- $\quad$ Scratch programming language, version 1.4.

- $\quad$ Xbox 360 Kinect sensor.

- $\quad$ Kinect2Scratch SDK compatible with PC and Windows 8 operating system, used to send data from the Kinect sensor to the Scratch language.

For its study, official pages of both Kinect2Scratch and sensor programming in the Scratch environment have been consulted, managing to find basic tools and functions that helped in the development of the software.

\section{Scratch programming language in version 1.4}

The Scratch language is a free software that allows users to use event-driven programming and owns multiple active objects called sprites. Sprites can be painted from vector graphics, bitmaps, can be painted online using a simple editor from Scratch's own website, and they can also be imported from external sources including webcams. For the development of this project, it was used Scratch version 1.4, which was developed and published in 2003 by the MIT Media Lab (laboratory within the School of Architecture and Planning at the Massachusetts Institute of Technology). [10]

This language stands out for its intuitive and didactic ability in addition to allowing an easy approach to programming by using an interface with "blocks", which represent the basic instructions of the classical programming, and in which can be performed animations, presentations, video games, etc.; this use of blocks avoids the use of a rigid programming syntax common in other types of languages. Figure 2 shows the interface of Scratch version 1.4; as mentioned, it is a language that uses scripts and sprites and its main motto is: program, create and play; which gives a clear idea of what its main intention is. [11]

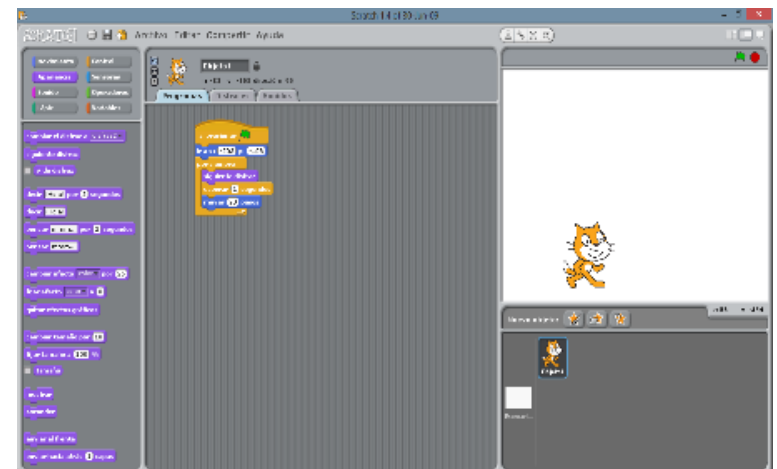

Fig. 2 Scratch graphical interface in version 1.4

This software allows to develop creative and computational ideas, some of its main features being the following:

- Intuitive and graphical interface.

- It has a resource bank in its own integrated development environment: objects, characters, scenarios, etc.

- Instant visualization of what is done in the program.

- Using blocks as code instead of text.

- Interaction with the objects and characters of the program on the screen. [12]

\section{Xbox 360 Kinect sensor}

Kinect is described as a revolution in manufacturing because it provides a new type of interaction with computers [13]. Kinect is a software-enabled device that can capture, track, and decrypt body movements, gestures, and voice. Audio and video information serves as commands to interact with digital content presented in games or software programs. It has a peripheral camera designed for the Xbox 360 gaming console by Microsoft Company Inc. [14]. Figure 3 shows the version of Kinect used by the Xbox 360. 


\section{International Advanced Research Journal in Science, Engineering and Technology}

Vol. 6, Issue 11, November 2019

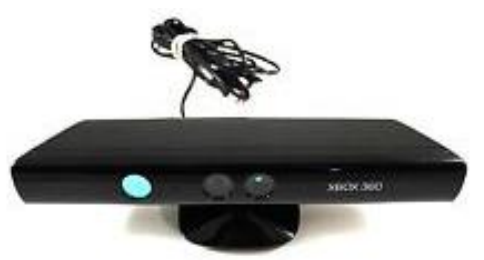

Fig. 3 Xbox 360 Kinect sensor.

Kinect has an RGB camera and two 3D depth sensors that provide a completely different experience than the traditional one. The combination of these sensors makes that the captured images can be seen in three dimensions, that is, on the $\mathrm{x}$ $y-z$ axes, thus being able to know the distance to which each of the objects in the image is located. In addition, its internal software makes it possible to recognize skeletons through a pattern that tells us that a body is formed by a head, a trunk, two arms and two legs, so that it separates the skeleton from the rest of the image obtained with the sensor [15].

Kinect was developed by Microsoft as a peripheral for its Xbox 360 video game console and was released in 2010. A year later, a PC-compatible version for Windows 7 (and later Windows 8) operating systems was released in addition to a free Software Development Kit (SDK) to give the community of academic developers and researchers the opportunity to work with the full power of the device.

Some of the features of this SDK [16] are mentioned below:

- Access to the unprocessed data flow of depth, color camera, and microphones.

- Skeletal tracking capability of up to two people for the creation of gesticulation applications.

- Audio processing: noise suppression, echo cancellation and, through the Windows API, speech recognition.

- $\quad$ Easy installation and extensive technical documentation.

\section{Kinect2Scratch}

Kinect2Scratch software was developed by Stephen Howell and allows data from the Kinect sensor to be sent to Scratch, allowing anyone to perform motion-controlled programs, use gestures, for the realization of games and kinesthetic programs, in addition to having fun while learning [17].

In order to interact with the real world and using the Kinect SDK, Stephen Howell developed a software capable of transmitting a large part of Kinect's own data to Scratch, and therefore giving users, for free, a new way of working and interacting with Scratch. The software required are a Windows 7 or 8 operating system, and the latest version of the Kinect SDK, which can be found on the Microsoft website. Once the Kinect and Kinect2Scratch SDK are installed, it is proceeded to launch the software and display the window as shown in Figure 4. This interface is very intuitive, and it provides quick access to all the options available in the software.

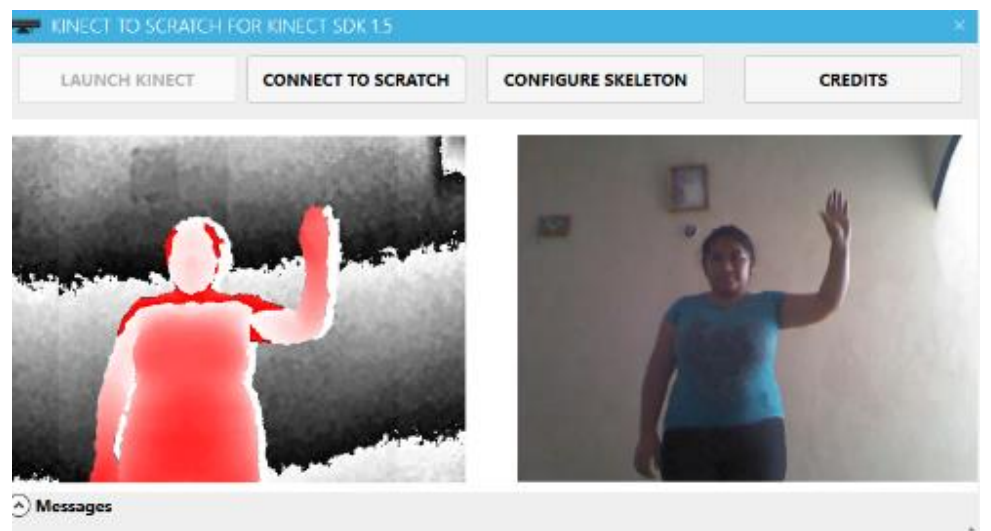

Fig. 4 Kinect2Scratch sensor.

\section{Software design}

In the development phase of the software, the first step was to design the user interface, which includes the design of different buttons and the recording of sounds for the objects implemented in it. The Kinect sensor was connected to the Scratch environment through the Kinect2Scratch SDK, subsequently, the behavior of the interface and each of its scenarios and objects were defined in the Scratch programming language version 1.4, and finally the appropriate response to user actions in each module was implemented.

In each scenario, a series of attractive visual objects and the use of sounds in the Mayan and English languages were implemented, always keeping in mind to be a support in the teaching-learning process. 


\section{International Advanced Research Journal in Science, Engineering and Technology}

Vol. 6, Issue 11, November 2019

\section{III.RESULTS}

As a result of this work, the software called AniMaIn was obtained, which has the following menu on the main screen (see Figure 1).
- Animals
- Pronouns
- Verbs
- Family
- $\quad$ Fruits and vegetables
- $\quad$ Exercises

The buttons that were implemented in the main menu allow the user to choose a specific category. Clicking on one displays a window to interact with the set of objects that are provided, as shown in Figure 5, which corresponds to the category of Animals. The objects displayed in each window according to the selected category appear randomly in a range of 0 to 10 seconds.

Each screen associated with a category includes an icon which allows the user to return to the main screen (as shown in the upper right corner of Figure 5, the figure of a house).

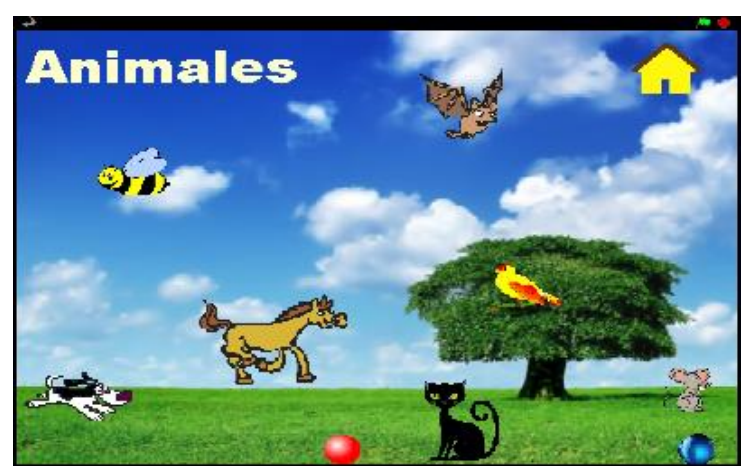

Fig. 5 Animals category of the developed software.

In each window displayed, two objects (red and blue circle) were configured to manipulate the user's left and right hand respectively. The interaction with Kinect was performed through these buttons.

In this sense the most important element of the game are the circles, which have as functionality to position themselves on an object according to the movement that the user makes and emit a sound that in this case is the name of the object that touches, in addition, it is accompanied by a sign with the object's name written either in Maya or English, as appropriate.

If the user who interacts with the software touches an object of the category that is presented with the blue circle, a word will be emitted in the Mayan language. Otherwise, if the same object is touched but using the red circle, the corresponding word in the English language will be emitted. The described process can be observed in Figure 6.

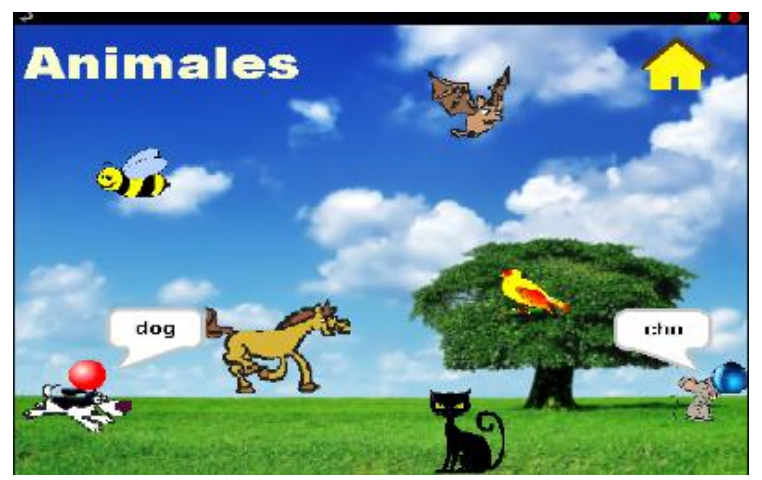

Fig. 6 Example of the functionality of the red and blue circles on each object.

The process described above corresponds to the Animals category, however, this is similar in all the other categories presented in this software, i.e. in "Pronouns", "Verbs", "Family" and "Fruits and Vegetables".

On the other hand, the software has a useful category for learning assessment: the Exercises category. This section is reached by selecting Exercises from Figure 1. 


\section{International Advanced Research Journal in Science, Engineering and Technology}

Vol. 6, Issue 11, November 2019

In the Exercises category, a red circle will be manipulated within the interface so that the user through the programmed sensor of the right hand chooses the correct options according to the objects that are presented to him in each scenario. An example of this can be seen in Figure 7.

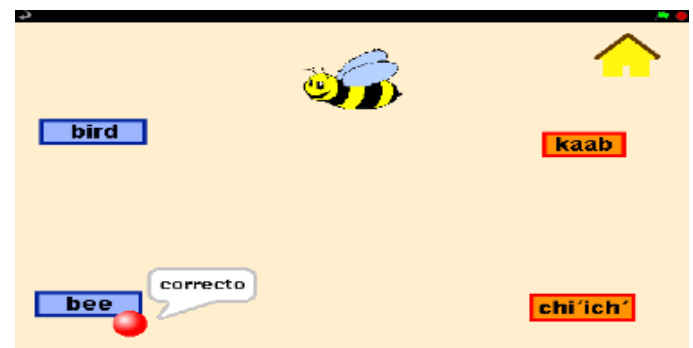

Fig. 7 Example of the functionality of the Exercises category.

As has been mentioned, one of the main elements of the software is the manipulation of the circles. Figure 8 shows an example of the functionality of the programmed sensor (left hand), which allows the red circle to stay inside the stage at all times and until the user is positioned on an object contained in the interface that is present, it will emit a sound of a Mayan word accompanied by its corresponding writing respecting a one second time interval.

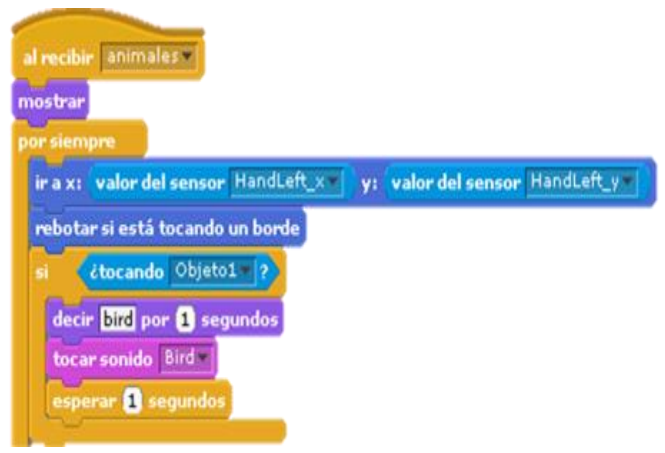

Fig. 8 Example of the code implemented in a category.

\section{IV.CONCLUSIONS}

The impact of information and communication technologies in our environment is increasing, therefore the importance of the contribution to the development of essential tools in the classroom such as educational software. At present, the impact of ICTs is increasing and one of its most important improvements is the way in which people can interact with them. Interactivity is the ability to respond contingently to the actions of users, which in this case are students. The term "interactivity", therefore, can be used in two ways: to describe technical interactivity (the way in which technology serves as an interface between the user and the study material), and to refer to pedagogical interactivity, which is in itself a teaching strategy. To improve classroom interactivity the proposed software can be exploited in classrooms as a didactic strategy for the teaching-learning process of students.

The basic tool presented in this work can be used as a teaching-learning strategy in the educational field to develop learning environments. This software is innovative and an excellent option as a methodological tool as it helps to invigorate the use of the Mayan language; this based on the crucial fact of preserving it and promoting community identity and community heritage by changing the traditional way of learning in the classroom in order to enable students to be more autonomous in the exploitation of technological tools.

As a future work of this project, the software will be evaluated by observing the behavior of students in the interaction with it and with the Kinect sensor as a teaching support tool in the development of skills.

\section{REFERENCES}

[1]. Kennewell S., Tanner H., Jones S., \& Beauchamp G. Analysing the use of interactive technology to implement interactive teaching. Journal of Computer Assisted Learning, vol. 24, pp. 61-73, 2008.

[2]. Vidal Ledo, María. Software educativo. En búsqueda digital, disponible en: http://scielo.sld.cu/pdf/ems/v24n1/ems12110.pdf

[3]. González, G. ¿Qué es software educativo?. En Imágenes de Software Educativo. Google. [citado 11 Nov 2009].. Disponible en: http://profesorinteractivo.blogia.com/2007/041701-que -es-software-educativo- .php 3

[4]. Huaytan (2012). Aplicación del software educativo multimedia en la enseñanza de las matemáticas para desarrollar un aprendizaje significativo. Universidad Privada San Pedro Chimbote. Pe Perú. http://repositorio.ucm.edu.co:8080/jspui/bitstream/handle/10839/838/Magda\%20Cecilia\%20Meneses\%20Osorio.pdf?sequence=1 


\section{International Advanced Research Journal in Science, Engineering and Technology}

Vol. 6, Issue 11, November 2019

[5]. Sanín S., Stella María. Diseño, Tecnología y Ambientes de Aprendizaje. Memorias XV Simposio Desarrollo y Nuevas Tecnologías, Escuela de Ciencias Sociales, Universidad Pontificia Bolivariana, 1996. Recuperado de: http://www.c5.cl/ntic/docs/software/metodologia.pdf

[6]. MEN (2004). Al Tablero. Recuperado el 17 de Noviembre de 2019, de http://www.mineducacion.gov.co/1621/article-87408.htm

[7]. Osorio Montoya, Silvia María. (2014). Software Educativo para el buen uso de las TIC. Universidad católica de Pereira.

[8]. Prieto, M., Pech, S., García, J. \& de León, T. (2015). Aprendizaje interactivo de la arquitectura Maya. En Aportaciones en el uso de las Tecnologías para el aprendizaje (61-66). Miami: CcCIATA. Recuperado https://www.researchgate.net/profile/Manuel_Prieto3/publication/291669425_Contributions_to_the_uses_of_Technology_for_Learning_2015/1 inks/56a49fdf08ae232fb2076fae.pdf

[9]. Guoron Ajquijay, Pedro. (2010). Ciencia y Tecnología Maya. Guatemala: ESEDIR-PRODESSA.

[10]. López, J. C. (2011). Programación con Scratch: Cuaderno de Trabajo para Estudiantes (Cuarta ed.). Cali: Eduteka.

[11]. URL: https://scratch.mit.edu/about/

[12]. Nieves, C. (2011). Scratch. Programación fácil para educación primaria y secundaria. Scratch. 1, 10.

[13]. The New Scientist. (2011). The Kinect revolution, 208 (2789).

[14]. icrosoft@. (2014). Presentando Kinect para Xbox 360. Consultado el 3 de julio del 2014, de la página web http://www.xbox.com/es-CO/Kinect

[15]. Fernández, E. (2012). Control de software educativo mediante Kinect de Microsoft. Universidad Carlos III de Madrid. 27-39. Recuperado de: http://earchivo.uc3m.es/bitstream/handle/10016/16846/TFG_Estefania_Fernandez_Sanchez.pdf?sequence=1

[16]. Wederago, J. (2013). Aprendizaje y desarrollo de aplicaciones multimedia e interactivas en entorno Scratch/BYOB con Arduino y Kinect. Pamplona. Pág.32 Recuperado de: http://academicae.unavarra.es/bitstream/handle/2454/7564/578088.pdf? sequence=1

[17]. Howell, S. (2012). Kinect2Scratch (Version 2.5) [Computer Software].. http://scratch.saorog.com 